\title{
Endothelial Dysfunction in Children with Juvenile Psoriatic Arthritis
}

\author{
Lenka Turoňová ${ }^{1}$, Kristína Kubejová2,*, Karolína Vorčáková ${ }^{3}$ Peter Ďurdík ${ }^{1}$, Tatiana Péčová3, \\ Klára Martinásková4
}

\section{ABSTRACT}

Background: To evaluate the presence of endothelial dysfunction in Slovak children with juvenile psoriatic arthritis in the absence of classic cardiovascular risk factors in order to assess its relationship to the disease activity and disability.

Methods: 25 juvenile psoriatic arthritis patients (JPSA) and 25 healthy controls aged 6-19 years were enrolled into this study. In all subjects vascular measurements over a period of three years (January 2013 - January 2016) were performed, in accordance with the guidelines for ultrasonographic evaluation of FMD\% (flow-mediated endothelial dependent vasodilatation) of the brachial artery. The measured items were compared to the variables reflecting the disease activity and disability.

Results: Significantly lower FMD\% values in patients with JPSA when compared to healthy controls \{mean(SD), median, range: 5.49\% (3.77), $3.55,0.3-13.0$ vs. 9.28\% (1.72), 9.3, 6.4-13.1\} ( $p<0.001$ ) have been documented. Strong correlations between FMD\% values and disease duration $(p<0.01)$, non-specific inflammatory markers levels $(p<0.001)$ or functional disability $(p<0.01)$ have been observed. Significantly lower FMD\% values in patients with an early disease onset (JPSA onset $<5$ years of age) when compared to the rest of JPSA group \{mean (SD), median, range: $4.39 \%$ (2.47), 4.45, 0.9-13.2 vs. 6.38\% (1.42), 6.3, 3.2-12.1\} ( $p<0.01$ ) have also been detected.

Conclusion: Study is the only one addressing endothelial dysfunction development in Slovak children with psoriatic arthritides. We state that endothelial dysfunction is present in these patients even during childhood and in the absence of classic cardiovascular risk factors. Its development seems to be related to an early disease onset as well as to the increased disease activity and disability. Potential genetic predictors have also been identified.

\section{KEYWORDS}

cardiovascular risk; endothelial dysfunction; psoriasis; arthritis; childhood

AUTHOR AFFILIATIONS

${ }^{1}$ Department of Pediatrics, Comenius University in Bratislava, Jessenius Faculty of Medicine in Martin and University Hospital Martin, Martin, Slovakia

${ }^{2}$ Department of Pediatrics and Adolescent Medicine, Pavol Jozef Šafárik University in Košice, Faculty of Medicine, Košice, Slovakia

${ }^{3}$ Department of Dermatology, Comenius University in Bratislava, Jessenius Faculty of Medicine in Martin and University Hospital Martin, Martin, Slovakia

${ }^{4}$ Department of Dermatology, A. Reiman's Hospital, Prešov, Slovakia

* Corresponding author: Department of Pediatrics and Adolescent Medicine, Pavol Jozef Šafárik University in Košice, Faculty of Medicine, Trieda SNP 1, 04001 Košice, Slovakia; e-mail: kristina.kubejova@yahoo.com

Received: 27 February 2018

Accepted: 7 August 2018

Published online: 12 December 2018

Acta Medica (Hradec Králové) 2018; 61(3): 79-85

https://doi.org/10.14712/18059694.2018.122

(c) 2018 The Authors. This is an open-access article distributed under the terms of the Creative Commons Attribution License (http://creativecommons.org/licenses/by/4.0), which permits unrestricted use, distribution, and reproduction in any medium, provided the original author and source are credited. 


\section{INTRODUCTION}

Association of adult-onset psoriatic arthritis (PsA) with relatively high risk of cardiovascular (CV) morbidity has been well established (1-14). Recent metaanalyses discovered that patients with PsA had a $43 \%$ higher risk of having (or developing) cardiovascular diseases compared to non-psoriatic individuals, while the risk of developing an incident cardiovascular event was 55\% higher in PsA patients compared with the general population. Furthermore, the risk of each of the individual cardiovascular outcomes was increased, including MI (68\%), cerebrovascular diseases (22\%), and heart failure (31\%) in PsA patients compared with the general population (3). The presence of psoriasis (PS) on the other hand largely contributes to this fact, regarding especially timeliness of its occurrence, its severity $(15,6)$ and in adults, frequent association with traditional CV risk factors and fully developed metabolic syndrome (17).

Moreover, the prevalence of CV manifestations in psoriatic arthritides exhibits strong correlations to the levels of non-specific inflammatory markers, as well as to the PS/ PsA duration (18). On the other hand, the question arises as to whether the risk of subclinical CV manifestations in psoriatic arthritides appears to be higher even in the low age groups, ie. in the groups of young children without presence of classic CV risk factors. However, it is assumed that the release of inflammatory markers and mediators at a stage of high disease activity significantly potentiates the formation of endothelial dysfunction (ED) and thus, despite the absence of conventional CV risk factors, might predispose to atherosclerosis (ATS) as well as the resulting complications. Whereas the inflammatory genesis of ED development is (under the same conditions) also expected during childhood, by contrast, the presence of ED in juvenile psoriatic arthritides (JPSA) remains very poorly defined (worldwide). Endothelial dysfunction represents a key step in the initiation and maintenance of atherosclerosis and may serve as a marker for future risk of cardiovascular events $(19,20)$. It can be noninvasively measured by detecting the postoclussive flow mediated vasodilation (FMD\%) of the brachial artery using high sensitive ultrasonography (B-mode) (20). This study was aimed to assess whether ED is present in children with JPSA in Slovakia (even providing the absence of classic CV risk factors) and to evaluate to what extent it is related to the disease activity and functional disability.

\section{MATERIAL AND METHODS}

The study was realized over a period of three years (January 2013 - January 2016). Children with JPSA aged 6-19 years $(n=25)$ and 25 healthy controls were included. Only patients fulfilling the ILAR (International League of Associations for Rheumatology) criteria for JPSA were included (21). These were as follows: 1) juvenile arthritis and psoriasis or 2) arthritis and at least two of the following a) dactylitis, b) nail pitting or onycholysis, c) positive family history of psoriasis in a first-degree relative. Patients with JPSA were sub-categorized in one of the following categories according to the characteristic patterns of joint involvement:
1) polyarticular onset, 2) monoarticular or assymetrical oligoarticular onset, 3) predominant involvement of the distal interphalangeal joints, 4) involvement of the sacroiliac joints. With regards to the ILAR exclusion criteria all included patients were rheumatoid factor (RF) negative. No family history of HLA B27 associated disease and no onset of arthritis in a male with HLA B27 antigen positivity after the age of 6 th. year were detected. Patients with systemic onset of juvenile idiopathic athritis were excluded.

We aimed to eliminate the presence of traditional CV risk factors in our study by expanding the exclusion criteria such as: 1) presence of hypertension (blood pressure $>95$.th percentile for given age, gender and body hight), 2) presence of diabetes mellitus (defined as fasting plasma glucose $\geq 7.0 \mathrm{mmol} / \mathrm{L}$ ), 3) prediabetes (defined as borderline fasting plasma glucose ranging from 5.6 to $6.9 \mathrm{mmol} / \mathrm{L}$ ), 4) dyslipidaemia (defined as total cholesterol $\geq 4.85 \mathrm{mmol} / \mathrm{L}$, low-density lipoprotein cholesterol $\geq 3.25 \mathrm{mmol} / \mathrm{L}$, high-density lipoprotein $\leq 0.85 \mathrm{mmol} / \mathrm{L}$, triacylglycerides $\geq 1.50 \mathrm{mmol} / \mathrm{L}$ ) 5) obesity (body mass index > 95.th percentile), 6) evident CV disease or positive history of well-defined atherosclerotic events, 7) smoking, 8) treatment with antihypertensive agents, antiaggregant drugs or estrogens. In all included subjects, the renal function values fell within the reference range.

Activity of JPSA was evaluated according to the criteria presented by Giannini et al. (22). Variables in the core set included: 1) physician global assessment of overall disease activity on visual analogue scale (VAS), range $0-10 \mathrm{~cm}$, 2) parent or patient global assessment of overall well-being on visual analogue scale (range $0-10 \mathrm{~cm}$ ), 3) assessment of functional disability (23), 4) number of joints with active arthritis, 5) number of joints with limited range of motion, and 6) markers of inflammation - erythrocyte sedimentation rate (ESR) or C-reactive protein (CRP) levels.

On the whole, the fasting plasma glucose, serum lipid profile, blood pressure values, body mass index (BMI), age at the JPSA onset, JPSA activity and disability as well as the JPSA duration were assessed. Moreover, some laboratory predictors of disease severity course (antinuclear antibodies and major histocompatibility complex class I and II) were evaluated. In all patients vascular measurements were performed, in accordance with the guidelines for FMD\% ultrasonographic evaluation of brachial artery as shown by Corretti et al. (24). The measurements were performed using high-resolution Doppler ultrasound (Acuson Antares 5.0, Siemens Medical Solutions).

Informed consent was obtained from all subjects or from their parents in underaged patients with prior approval of the ethics committee in Martin, Slovakia. All procedures performed in studies involving human participants were in accordance with the ethical standards of the institutional research committee and with the 1964 Helsinki declaration and its later amendments or comparable ethical standards.

\section{STATISTICAL ANALYSIS}

The results have been analyzed using statistical program SPSS (version 14.0, SPSS Inc., Chicago, IL 60606-6412, 
USA). Continuous data have been expressed as mean \pm standard deviation (SD), median and range. Categorical data have been presented directly as numeric and percentage expression. We compared categorical data and proportions using the chi-square test or Fisher's exact test as indicated. FMD\% values have been compared using the Mann-Whitney test. The correlation between continuous variables was assessed using Pearson's linear correlation coefficients $(\mathrm{r}) . \mathrm{P} \leq 0.05$ has expressed a statistically significant difference between the compared variables.

\section{RESULTS}

Demographic, clinical and laboratory features of children with JPSA are shown in Table 1. Most patients of the JPSA group (76\%) were treated with NSAID (non-steroidal antirheumatic drugs), of that $14(56 \%)$ children received naproxen in a dose of $10-20 \mathrm{mg} / \mathrm{kg} / \mathrm{day}, 5(20 \%)$ patients received ibuprofen in a dose of $30-40 \mathrm{mg} / \mathrm{kg} / \mathrm{day}$. No patient was treated with systemic corticosteroids. At the time of study, 21 (84\%) patients were using Disease Modifying Antirheumatic Drugs (DMARDs). 18 (72\%) were taking methotrexate in a dose of $0.3-0.5 \mathrm{mg} / \mathrm{kg}$ once a week, $2(8 \%)$ of patients received sulphasalazine in a dose of $50 \mathrm{mg} / \mathrm{kg} /$ day. 1 (4\%) patient received adalimumab (40 mg once per 14 days).
The outcome showed a significantly lower FMD\% values in patients with JPSA when compared to healthy controls \{mean (SD), median, range: $5.49 \%$ (3.77), 3.55, $0.3-13$ vs. 9.28\% (1.72), 9.3, 6.4-13.1\} ( $\mathrm{p}<0.001)$. We have also detected the significant correlations between FMD\% and the level of CRP or ESR values $(p<0.001)$. Likewise, in patients with JPSA the significant correlations between FMD\% values and disease duration $(p<0.01)$, CHAQ (Childhood Health Assessment Questionnaire) disability index (range 1-3) $(p<0.01)$ and physician global assessment of disease activity on the visual analogue scale (VAS) $(p<0.01)$ have been observed. No significant relations have been detected between the FMD\% values and values of assessed traditional CV risk factors. The interpretation of data is shown in Tables 2 and 3 . We also compared some clinical and laboratory features between early-onset JPSA group with remaining JPSA patients (we used age 5 years as the cut-off based on our previous findings) (25). Significantly lower $\mathrm{FMD} \%$ values in patients with an early disease onset when compared to the rest of JPSA group (late onset JPSA) \{mean (SD), median, range: $4.39 \%$ (2.47), 4.45, 0.9-13.2 vs. $6.38 \%(1.42), 6.3,3.2-12.1\}(\mathrm{p}<0.01)$ have been detected. Similarly, in early-onset JPSA subgroup significantly higher frequency of the presence of HLA DRw8, HLA DR 5 or both $(p<0.005)$ has been documented. Moreover, higher degree of functional disability (CHAQ) and disease activity (number of swollen joints, number of painful

Tab. 1 Characteristic of JPSA patients.

\begin{tabular}{|c|c|c|c|}
\hline Variable & $\begin{array}{l}\text { Patients } \\
(n=25)\end{array}$ & $\begin{array}{l}\text { Controls } \\
(n=25)\end{array}$ & P value \\
\hline $\begin{array}{l}\text { Age (years), mean } \pm \text { SD } \\
\text { At time of this study } \\
\text { At the time of JPSA onset }\end{array}$ & $\begin{array}{l}13.91 \pm 2.98 \\
8.43 \pm 2.83\end{array}$ & $14.01 \pm 3.0$ & 0.34 \\
\hline Boys/Girls & $11 / 14$ & $11 / 14$ & 1.00 \\
\hline Age $<5$ years at the time of JPSA onset, $n(\%)$ & $12(48 \%)$ & & \\
\hline JPSA Duration (years) & $5.48 \pm 3.91$ & & \\
\hline $\begin{array}{l}\text { JPSA Activity and disability } \\
\text { No. of swollen joints } \\
\text { No. of painful joints } \\
\text { No. of joints with limited ROM } \\
\text { VAS } 1(0-10 \mathrm{~cm}) \\
\text { VAS } 2(0-10 \mathrm{~cm}) \\
\text { CRP }(\mathrm{mg} / \mathrm{L}) \\
\text { ESR (mm/hour) } \\
\text { CHAQ disability index (range } 1-3) \\
\text { Morning stiffness (min.) }\end{array}$ & $\begin{array}{l}2.0 \pm 1.2 \\
2.91 \pm 1.57 \\
2.12 \pm 1.34 \\
2.6 \pm 1.4 \\
2.8 \pm 1.7 \\
12.82 \pm 8.58 \\
17.91 \pm 8.6 \\
0.81 \pm 0.54 \\
17.5 \pm 10.58\end{array}$ & $\begin{array}{l}2.29 \pm 1.4 \\
5.91 \pm 3.43 \\
0.00 \pm 0.02\end{array}$ & $\begin{array}{l}<0.001 \\
<0.001 \\
<0.01\end{array}$ \\
\hline $\begin{array}{l}\text { Other JPSA characteristics } \\
\text { Polyarticular onset, } \mathrm{n}(\%) \\
\text { Mono- or assymetrical oligoarticular onset, } \mathrm{n}(\%) \\
\text { Predominat impairment of DIP, } \mathrm{n}(\%) \\
\text { Sacroiliitis, } \mathrm{n}(\%) \\
\text { Nail changes, } \mathrm{n}(\%) \text {, anytime during the course of disease } \\
\text { Dactylitis, } \mathrm{n}(\%) \text {, anytime during the course of disease } \\
\text { Enthesitis, } \mathrm{n}(\%) \text {, at the time when the examination is carried out } \\
\text { ANA, } \mathrm{n}(\%) \\
\text { HLA B27, } \mathrm{n}(\%)\end{array}$ & $\begin{array}{l}5(20 \%) \\
20(80 \%) \\
8(32 \%) \\
3(12 \%) \\
18(72 \%) \\
13(52 \%) \\
7(28 \%) \\
13(52 \%) \\
7(28 \%)\end{array}$ & & \\
\hline
\end{tabular}

Values in the table are expressed as mean \pm SD or number and percentage expressing.

JPSA = juvenile psoriatic arthritis, $n=$ number of subjects, ROM = range of moving, VAS 1 = visual analogue scale 1 (physician global assessment of overall disease activity on visual analogue scale), VAS 2 = visual analogue scale 2 (parent or patient global assessment of overall well-being on visual analogue scale), $\mathrm{CRP}=\mathrm{C}$-reactive protein, ESR = erythrocyte sedimentation rate (Westergren method), CHAQ = Childhood Health Assessment Questionnaire, DIP = distal interphalangeal joints, ANA = antinuclear antibodies, HLA = Human Leukocyte Antigen 
joints, number of joints with limited mobility, CRP/ESR, VAS) has been observed ( $\mathrm{p}$ for all the above listed $<0.01$ ) in early-onset JPSA subgroup. The interpretation of data is shown in Table 4. We also compared the FMD\% values in the group of patients with JPSA treated with NSAIDs with the values in the non-NSAID group of patients with JPSA. Even though we observed higher FMD\% values in the group of patients treated with NSAIDs, statistically significant differences between the compared groups were not confirmed (mean (SD), median, range, NSAID group: $5.59 \%$ (1.47), 5.55, 2.8-13.2 vs. non-NSAID group: $5.36 \%$ (1.44), 5.3, 0.8-11.1\} ( $\mathrm{p}=0.81$ ). While evaluating the conventional CV risk factors we have not observed any statistically significant differences between the group of patients with JPSA and the control group of healthy children.

Tab. 2 Evaluated traditional CV risk factors.

\begin{tabular}{|l|l|l|l|}
\hline Variable & $\begin{array}{l}\text { Patients } \\
(\mathbf{n}=\mathbf{2 5}) \\
\text { Mean } \pm \text { SD }\end{array}$ & $\begin{array}{l}\text { Controls } \\
\text { (n= 25) } \\
\text { Mean } \pm \text { SD }\end{array}$ & P value \\
\hline Blood pressure (percentile) & $\begin{array}{l}59.62 \pm \\
10.43\end{array}$ & $60.0 \pm 10.1$ & 0.78 \\
\hline $\begin{array}{l}\text { Body mass index (percen- } \\
\text { tile) }\end{array}$ & $\begin{array}{l}55.25 \pm \\
7.39\end{array}$ & $\begin{array}{l}55.33 \pm \\
6.88\end{array}$ & 0.93 \\
\hline Total cholesterol (mmol/L) & $3.85 \pm 0.38$ & $3.82 \pm 0.37$ & 0.71 \\
\hline HDL(mmol/L) & $1.29 \pm 0.27$ & $1.37 \pm 0.26$ & 0.23 \\
\hline LDL (mmol/L) & $2.15 \pm 0.35$ & $2.12 \pm 0.31$ & 0.48 \\
\hline Triglycerides (mmol/L) & $0.52 \pm 1.6$ & $0.48 \pm 0.18$ & 0.88 \\
\hline $\begin{array}{l}\text { Fasting plasma glucose } \\
\text { (mmol/L) }\end{array}$ & $4.59 \pm 0.58$ & $4.55 \pm 0.48$ & 0.80 \\
\hline $\begin{array}{l}\text { FMD\% values } \\
\text { mean (SD), } \\
\text { median, } \\
\text { range }\end{array}$ & $\begin{array}{l}5.49 \% \\
(3.77), 3.55\end{array}$ & $\begin{array}{l}9.28 \% \\
(1.72), 9.3\end{array}$ & $<0.001$ \\
\hline
\end{tabular}

Values in the table are expressed as mean \pm SD, CV = cardiovascular, $\mathrm{HD}=$ high-density lipoprotein, $\mathrm{LDL}=$ low-density lipoprotein, $\mathrm{FMD} \%=$ postoclussive flow-mediated vasodilation

Tab. 3 Correlation of FMD\% in patients with JPSA with selected variables.

\begin{tabular}{|l|l|l|}
\hline Variable & r & P value \\
\hline Age at the time of study & -0.247 & 0.24 \\
\hline JPSA duration & -0.755 & $<0.01$ \\
\hline CHAQ disability index (range 0-3) & -0.733 & $<0.01$ \\
\hline VAS (range 0-10 cm) & -0.715 & $<0.01$ \\
\hline ESR & -0.850 & $<0.001$ \\
\hline CRP & -0.901 & $<0.001$ \\
\hline
\end{tabular}

JPSA = juvenile psoriatic arthritis, $\mathrm{CHAQ}=$ Childhood Health Assessment Questionnaire, VAS = visual analogue scale (physician global assessment of overall disease activity on visual analogue scale), ESR = erythrocyte sedimentation rate (Westergren method), CRP $=$ C-reactive protein

\section{DISCUSSION}

The very existence of cutaneous psoriasis, even in the absence of joint disease, has been linked to accelerated ATS. A 2014 systematic review of 20 studies of endothelial
Tab. 4 Comparison of patients with early-onset JPSA with those with late-onset JPSA.

\begin{tabular}{|c|c|c|c|}
\hline Variable & $\begin{array}{l}\text { Early-onset } \\
\mathrm{N}=12\end{array}$ & $\begin{array}{l}\text { Late-onset } \\
\mathrm{N}=13\end{array}$ & $P$ value \\
\hline $\begin{array}{l}\text { JPSA duration, (years), } \\
\text { mean } \pm \text { SD }\end{array}$ & $6.5 \pm 2.4$ & $4.8 \pm 3.0$ & $<0.01$ \\
\hline Females, $\mathrm{n}(\%)$ & $9(75 \%)$ & $4(30.8 \%)$ & $<0.01$ \\
\hline $\begin{array}{l}\text { Age of onset (years), } \\
\text { mean } \pm \text { SD }\end{array}$ & $2.3 \pm 1.4$ & $10.88 \pm 3.4$ & $<0.001$ \\
\hline $\begin{array}{l}\text { CHAQ disability index } \\
(0-3) \text {, mean } \pm \text { SD }\end{array}$ & $1.13 \pm 0.13$ & $0.63 \pm 0.38$ & $<0.01$ \\
\hline $\begin{array}{l}\text { ESR (mm/hour), mean } \\
\pm \mathrm{SD}\end{array}$ & $24.6 \pm 8.4$ & $15.8 \pm 3.5$ & $<0.01$ \\
\hline $\mathrm{CRP}(\mathrm{mg} / \mathrm{L})$, mean $\pm \mathrm{SD}$ & $15.8 \pm 8.3$ & $8.85 \pm 7.5$ & $<0.01$ \\
\hline No. of swollen joints & $3.0 \pm 6.16$ & $1.0 \pm 3.3$ & $<0.01$ \\
\hline No. of painful joints & $4.4 \pm 10.2$ & $1.4 \pm 6.9$ & $<0.01$ \\
\hline $\begin{array}{l}\text { No. of joints with limited } \\
\text { ROM }\end{array}$ & $3.3 \pm 6.5$ & $0.9 \pm 3.2$ & $<0.01$ \\
\hline $\operatorname{VAS}(0-10 \mathrm{~cm})$ & $3.6 \pm 3.2$ & $1.6 \pm 3.2$ & $<0.01$ \\
\hline HLA DRw8 (\%) & $7(58.3 \%)$ & $1(7.6 \%)$ & $<0.005$ \\
\hline HLA DR $5(\%)$ & $6(50 \%)$ & $1(7,6 \%)$ & $<0.005$ \\
\hline HLA B $27(\%)^{*}$ & $0(0 \%)$ & $7(53.8 \%)$ & $<0.001$ \\
\hline ANA (\%) & $8(66.6 \%)$ & $5(38.4 \%)$ & $<0.05$ \\
\hline $\begin{array}{l}\text { FMD\% values } \\
\text { mean }(S D) \text {, } \\
\text { median, } \\
\text { range }\end{array}$ & $\begin{array}{l}4.39 \% \\
(2.47), \\
4.45 \\
0.9-13.2\end{array}$ & $\begin{array}{l}6.38 \% \\
(1.42) \\
6.3 \\
3.2-12.1\end{array}$ & $<0.01$ \\
\hline
\end{tabular}

JPSA = juvenile psoriatic arthritis, CHAQ = Childhood Health Assessment Questionnaire, ESR = erythrocyte sedimentation rate (Westergren method), CRP = C-reactive protein, HLA = Human Leukocyte Antigen, ANA = antinuclear antibodies, FMD\% = postoclussive flow-mediated vasodilation; *Note: Three HLA B 27-positive boys with the onset of the disease between year 5 and year 6 of their lives were included in the group

function in psoriasis patients found that FMD\% was significantly impaired in the majority of studies (26). Some data suggest that the likelyhood of endothelial dysfunction is correlated with disease severity or disease duration (26). Interestingly, increased carotid intima-media thickness, a measure of subclinical ATS, has been demonstrated repeatedly in patients with PS and has been shown to correlate with FMD\% $(26,27)$. Taken together, these data suggest that patients with psoriasis display impaired endothelial-dependent relaxation and that this may correlate with future development of ATS. On the other hand, with the concurrent presence of arthritis and psoriasis, the $\mathrm{CV}$ risk might be even higher. Polachek et al. assessed the magnitude of risk of cardiovascular and cerebrovascular morbidity in patients with adult form of psoriatic arthritis (PsA) compared with the general population through a systematic review and meta-analysis of observational studies. Eleven studies, comprising 32,973 patients with PsA, were evaluated. There was a $43 \%$ increased risk of cardiovascular diseases in patients with PsA compared with the general population (pooled odds ratio [OR] 1.43 [95\% confidence interval (95\% CI) 1.24-1.66]). The risk of incident of cardiovascular events was increased by $55 \%$ (pooled OR1.22-1.96). Morbidity risks for myocardial in- 
farction, cerebrovascular diseases, and heart failure were increased by $68 \%, 22 \%$, and $31 \%$, respectively (pooled OR 1.68 [95\% CI 1.31-2.15], pooled OR 1.22 [95\% CI 1.05-1.41], and pooled OR 1.31 [95\% CI 1.11-1.55] (3).

Juvenile psoriatic arthritis (JPSA), on the other hand, is probably the most discussed and controversial of the various forms of childhood arthritides. Part of the debate derives from its characterisation as a single diagnostic category in current classifications, despite numerous demonstrations of its heterogeneous nature (28). In JPSA, it is necessary to distinguish between at least two different clinical phenotypes. Some of the children with JPSA can certainly be included in the SEA syndrome (seronegative - enthesitis - arthritis), which we also called juvenile spondyloarthropathy in the past, but the second group, are ANA positive early-onset children with clinical signs characteristic of JIA.

Children with JPSA, however, are exposed to various proatherogenic insults, but unlike the adult-forms of PsA, prevalence of subclinical atherosclerosis remains poorly defined in these patients. The exact mechanism of the predisposition to cardiovascular disease in psoriasis and psoriatic arthritides has not been explained satisfactorily. It has been suggested that three factors contribute to the cardiovascular risk profile. First, systemic and chronic inflammation due to the persistent secretion of tumour necrosis factor alpha and other proinflammatory cytokines plays a major role in the excessively high cardiovascular risk $(29,30)$. Second, comorbidities, such as smoking, diabetes mellitus, hypertension, metabolic syndrome and dyslipidaemia (have been exluded in our study). The third factor is the atherogenic side effects of systemic therapy. Recent results of some meta-analyses that are assessing associations between CV events and use of TNF (tumor necrosis factor) inhibitors, methotrexate, NSAIDs and glucocorticosteroids (GCs) in adult patients with RA (rheumatoid arthritis) or PS/PsA patients show, that NSAIDs treatment increased the risk of all CV events (RR, 1.18; $95 \%$ CI 1.01 to $1.38 ; \mathrm{p}=0.04$ ) as well as strokes. This effect is mostly driven by cyclooxygenase-2 (COX-2) inhibitors (RR, 1.36; 95\% CI 1.10 to $1.67 ; \mathrm{p}=0.004$ ) rather than non-selective NSAIDs (RR, 1.08 ; $95 \%$ CI 0.94 to $1.24 ; p=0.28$ ). The potential negative cardiovascular effects of corticosteroids are well known but not strongly evidence-based (31, 32). Corticosteroids may modulate the risk of cardiovascular disease in rheumatoid patients in two competing ways by increasing the risk due to deleterious effects on lipids, glucose tolerance, weight gain and hypertension, but on the other hand, potentially decreasing the risk by exerting antiinflammatory and antiproliferative effects on vascular wall (33). Furthermore, GCs may result in two independent effects over a time: an immediate effect of current exposure and a long-term cumulative effect of past exposure $(31,34)$. The same authors also quote that, corticosteroids are linked to the increased risk of all CV events (RR, 1.47; $95 \%$ CI 1.34 to $1.60 ; \mathrm{p}<0.001)$, as well as risk of myocardial infarction, stroke and heart failure in RA patients (31, 34). On contrary to this, the systemic treatment of patients with PS/PsA was associated with a significant decrease in risk of all the CV events ( $R R, 0.75 ; 95 \%$ CI 0.63 to 0.91 ; $\mathrm{p}=0.003$ ). The new biological treatments with a specific target, such as suppression of systemic inflammation by anti TNF - therapy, tend to be associated with concomitant risk reduction of the $\mathrm{CV}$ events in all abovementioned diseases. However, there is a need for further research focused on the role of recent biological treatments effects on patients with CV risk profile. Overall, all PsA patients have higher prevalence of CV comorbidities, including diabetes and hypertension, than the general population ( 35 , 36). Besides that, women's prevalence rate for CV risk is higher than men's due to a higher prevalence of metabolic syndrome and a high blood pressure. Costa et al. reported that HDL-cholesterol was increased and triacylglycerides were decreased in PsA patients treated with adalimumab (37). According to the same authors, the PsA patients treated with etanercept had decreased level of triacylglycerides (37). However other two studies did not prove a significant change $(36,38)$. There were no significant effects on total cholesterol, LDL-cholesterol, atherogenic index, or Apolipoprotein B : Apolipoprotein A-1 ratio (36, 38). Among children with JIA, treatment with etanercept significantly decreased total cholesterol, LDL-cholesterol, triacylglycerides, and CRP, but not HDL-cholesterol (39). However, this overall improvement in lipid profile and inflammation did not translate into improvement in atherogenic index.

Our study is the only one addressing ED development in Slovak children with juvenile psoriatic arthritides. The results are suggesting that ED development could be present even during childhood and in the absence of the traditional cardiovascular risk factors in these groups. Observation of significant relations between FMD\% values and non-specific inflammatory markers levels and other variables reflecting the disease activity in our study leads us to believe that systemic inflammation can be regarded as dominant CV morbidity predictor in these JPSApatients. The vascular endothelium is known to be a target of TNF- $\alpha$ (tumor necrosis factor- $\alpha$ ), which significantly participates in pathogenesis of the diseases. Circulating T-lymphocytes and monocyte-derived macrophages isolated from PSA patients produce increased amount of TNF- $\alpha$ in comparison with macrophages isolated from healthy patients. Futhermore, levels of TNF- $\alpha$ in PSA patients are elevated in the synovial tissue and skin lessions and correlate with disease activity $(40,41)$. On a cellular level, TNF- $\alpha$ induces theexpression of genes associated with inflammation, coagulation and proliferation. Decreased NO bioavailability appears to be a common and critical step linking TNF- $\alpha$ to endothelial dysfunction. TNF- $\alpha$ exerts its effects on the endothelium through its receptor (TNFR). Binding of TNFR by TNF- $\alpha$ leads to diminished eNOS (endothelial nitric oxide synthase) protein expression via suppression of promoter activity and destabilization of its mRNA. TNFR suppresses eNOS activity by preventing the degradation of its endogenous inhibitor ADMA (asymmetric dimethylarginine). TNFR signaling also induces the transcription factor NF- $\kappa$ B leading to enhanced expression of intercellular adhesion molecules (ICAM-1: intercellular adhesion molecule-1; VCAM-1: vascular cell adhesion molecule-1) $(41,42)$. Moreover, the long-lasting chronic inflammation may act as a promoter of oxidative processes, insulin resistance, and dyslipidemia that definitely have to be considered in the ED development (41-47). In this context, the 
early investigation of ED in active JPSA patients (even in the absence of traditional CV risk factors) might prevent severe complications during adulthood.

Physical inactivity, on the other hand, is another modifiable risk factor for premature atherosclerosis according to some authors. A study in adolescents and young adults by Edwards et al. (48) showed that higher physical activity was an independent positive predictor for lower arterial stiffness, measured as peripheral arterial distensibility and AIx (augmentation index). In this meaning, the detection of significant correlations between CHAQ disability index (functional impairrment) and FMD\% values in our study suggests, that chronic inflammation, when associated with higher degree of functional disability, could significantly influence the ED development. The amplifications of above mentioned considerations is assumed in relation to the observed significant correlations between FMD\% and early onset of the disease, since in our study the early JPSA onset was associated with higher degree of disease activity as well asfunctional impairment. Also, in patients with early-onset JPSA, we observed the presence of HLA DR5 and HLA DRw8 antigens. In association with the possible partial distortion of our results, we have to mention, that treatment with DMARDs might be associated with a significant decrease of inflammation, degree of disease disability as well as with reduction in diastolic and systolic blood pressure values and lipids profile (49). Methotrexate, an inhibitor of folic acid metabolism, can directly improve endothelium-dependent vasodilation in patients with inflammatory arthritides (although the data are limited) $(50,51)$, as it reduces the systemic inflammation and improves synovitis in patients with inflammatory arthritides. Anti-TNF- $\alpha$ inhibitors, on the other hand, also improve endothelium-dependent vasodilation in these patients $(52,53)$ and correlates with improvement in disease activity and markers of systemic inflammation (16). Last but not least, it should be mentioned that due to the low prevalence of JPSA in our country, our group of patients is relatively small. Therefore, to get more relevant results, combining outcomes of several national and international centers seems to be more beneficial.

\section{CONCLUSIONS}

It can be concluded that endothelial dysfunction is present in patients with JPSA even during childhood and in the absence of classic CV risk factors - not only in association with increased disease activity and disability, but also if JPSA is associated with an early onset or in relation to prolonged JPSA duration. It appears to be desirable, therefore, to evaluate the presence of ED in patients with JPSA. A desired objective of further research is to examine the possibility of early intervention in those children in order to prevent the future ATS development with resulting complications in adulthood.

\section{ACKNOWLEDGMENTS}

This work was supported by Ministry of Health, Slovac Republic. Grant No. 2012/28-UKMA-5.

\section{INFORMED CONSENT}

Informed consent was obtained from all subjects with prior approval of the ethics committee in Martin, Slovakia. Informed written consent was obtained from each patient.

\section{REFERENCES}

1. Ogdie A, Yu Y, Haynes K, et al. Risk of major cardiovascular events in patients with psoriatic arthritis, psoriasis and rheumatoid arthritis: a population-based cohort study. Ann Rheum Dis 2015; 74(2): 326-32.

2. Ernste FC, Sánchez-Menéndez M, Wilton KM, Crowson CS, Matteson EL, Maradit Kremers H. Cardiovascular risk profile at the onset of psoriatic arthritis: a population-based, cohort study. Arthritis Care Res 2015(7); 67: 1015-21.

3. Polachek A, Touma Z, Anderson M, Eder L. Risk of Cardiovascular Morbidity in Patients With Psoriatic Arthritis: A Meta-Analysis of Observational Studies. Arthritis Care Res 2017; 69(1): 67-74.

4. Ahlehoff $\mathrm{O}$, Gislason GH, Charlot M, et al. Psoriasis is associated with clinically significant cardiovascular risk: a Danish nationwide cohort study. J Intern Med 2011(2); 270: 147-57.

5. Kondratiouk S, Udaltsova N, Klatsky AL. Associations of psoriatic arthritis and cardiovascular conditions in a large population. Perm J 2008(4); 12: 4-8.

6. Gladman DD, Ang M, Su L, Tom BD, Schentag CT, Farewell VT. Cardiovascular morbidity in psoriatic arthritis. Ann Rheum Dis 2009; 68(7): 1131-5.

7. Han C, Robinson DW Jr., Hackett MV, Paramore LC, Fraeman KH, Bala MV. Cardiovascular disease and risk factors in patients with rheumatoid arthritis, psoriatic arthritis, and ankylosing spondylitis. J Rheumatol 2006; 33(11): 2167-72.

8. Ogdie A, Yu Y, Haynes K, et al. Risk of major cardiovascular events in patients with psoriatic arthritis, psoriasis and rheumatoid arthritis: a population-based cohort study. Ann Rheum Dis 2015; 74(2): 326-32.

9. Gulati AM, Semb AG, Rollefstad S, et al. On the HUNT for cardiovascular risk factors and disease in patients with psoriatic arthritis: population-based data from the Nord-Trondelag Health Study. Ann Rheum Dis 2016; 75(5): 819-24.

10. Kibari A, Cohen A, Bitterman H, et al. Cardiac and cardiovascular morbidities in patients with psoriatic arthritis: a population-based cohort study. Ann Rheum Dis 2014; 73: 730-1.

11. Li WQ, Han JL, Manson JE, et al. Psoriasis and risk of nonfatal cardiovascular disease in US women: a cohort study. Br J Dermatol 2012; 166(4): 811-8.

12. Love TJ, Solomon DH, Karlson EW. The risk of myocardial infarction among patients with psoriatic arthritis. Arthritis Rheum 2010; 62 Suppl 10: 793.

13. Sommer DM, Jenisch S, Suchan M, Christophers E, Weichenthal M. Increased prevalence of the metabolic syndrome in patients with moderate to severe psoriasis. Arch Dermatol Res 2006; 298(7):321-8.

14. Bengtsson K, Forsblad-d'Elia H, Lie E, et al. Are ankylosing spondylitis, psoriatic arthritis and undifferntiated spondyloarthritis associated with an increased risk of cardiovascular disease? Arthritis Rheumatol 2015; 67 Suppl 10: 1057.

15. Mallbris L, Akre O, Granath F, et al. Increased risk for cardiovascular mortality in psoriasis inpatients but not in outpatients. Eur J Epidemiol 2004; 19(3): 225-30.

16. Galarraga B, Belch JJ, Pullar T, Ogston S, Khan F. Clinical improvement in rheumatoid arthritis is associated with healthier microvascular function in patients who respond to antirheumatic therapy. J Rheumatol 2010; 37(3): 521-8. 
17. Asha K, Sharma SB, Singal A, Aggarwal A. Association of carotid intima-media thickness with leptin and apoliprotein b/apoliprotein a-I ratio reveals imminent predictors of subclinical atherosclerosis in psoriasis patients.Acta Medica (Hradec Králové) 2014; 57(1): 21-7.

18. Kimhi O, Caspi D, Bornstein NM, et al. Prevalence and risk factors of atherosclerosis in patients with psoriatic arthritis. Semin arthritis Rheum 2007; 36(4): 203-9.

19. Brunner H, Cockcroft JR, Deanfield J, et al. Working Group on Endothelins and Endothelial Factors of the European Society of Hypertension. Endothelial function and dysfunction. Part II: Association with cardiovascular risk factors and diseases. J Hypertens 2005; 23(2): 233-46

20. Deanfield J, Donald A, Ferri C, et al. Working Group on Endothelin and Endothelial Factors of the European Society of Hypertension. Endothelial function and dysfunction. Part I: Methodological issues for assessment in the different vascular beds. J Hypertens 2005; 23(1): 7-17.

21. Petty RE, Southwood TR, Manners P, et al. International League of Associations for Rheumatology. International League of Associations for Rheumatology classification of juvenile idiopathic arthritis. J Rheumatol 2004; 31(2): 390-2.

22. Giannini EG, Ruperto N, Ravelli A, Lovell DJ, Felson D, Martini A. Preliminary definition of improvement in juvenile arthritis. Arthritis Rheumatism 1997; 40(7): 1202-9.

23. Singh G, Athreya BH, Fries JF, Goldsmith DP. Measurement of health status in children with juvenile rheumatoid arthritis. Arthritis Rheum 1994; 37(12): 1761-9.

24. Corretti MC, Anderson TJ, Benjamin EJ, et al. International Brachial Artery Reactivity Task Force.Guidelines for the ultrasound assessment of endothelial-dependent flow-mediated vasodilation of the brachial artery: a report of the International Brachial Artery Reactivity Task Force. J Am Coll Cardiol 2002; 39(2): 257-65.

25. Stoll ML, Zurakowski D, Nigrovic LE, Nichols DP, Sundel RP, Nigrovic PA. Patients with juvenile psoriatic arthritis comprise two distinct populations. Arthritis Rheum 2006; 54(11): 3564-72.

26. Brezinski EA, Follansbee MR, Armstrong EJ, Armstrong AW. Endothelial dysfunction and the effects of TNF inhibitors on the endothelium in psoriasis and psoriatic arthritis. Curr Pharm Des 2014; 20(4): 513-28

27. Balci DD, Balci A, Karazincir S, et al. Increased carotid artery intima-media thickness and impaired endothelial function in psoriasis. J Eur Acad Dermatol Venereol 2009; 23(1): 1-6.

28. Ravelli A, Consolaro A, Schiappapietra B, Martini A. The conundrum of juvenile psoriatic arthritis. Clin Exp Rheumatol 2015; 33: 40-3.

29. Hansson GK, Robertson AK, Söderberg-Nauclér C. Inflammation and atherosclerosis. Annu Rev Pathol 2006; 1: 297-329.

30. Wakkee M, Thio HB, Prens EP, Sijbrands EJ, Neumann HA. Unfavorable cardiovascular risk profiles in untreated and treated psoriasis patients. Atherosclerosis 2007; 190(1): 1-9.

31. Roubille C, Richer V, Starnino T, et al. The effects of tumour necrosis factor inhibitors, methotrexate, non-steroidal anti-inflammatory drugs and corticosteroids on cardiovascular events in rheumatoid arthritis, psoriasis and psoriatic arthritis: a systematic review and meta-analysis. Ann Rheum Dis 2015; 74(3): 480-489.

32. Roubille C, Martel-Pelletier J, Davy JM, et al. Cardiovascularadverse effects of anti-inflammatory drugs. Antiinflamm Antiallergy Agents MedChem 2013; 12(1): 55-67.

33. Panoulas VF, Douglas KM, Stavropoulos-Kalinoglou A, et al. Longterm exposure to medium-dose glucocorticoid therapy associates with hypertension in patients with rheumatoid arthritis. Rheumatology 2008; 47(1): 72-5.

34. Avina-Zubieta JA, Abrahamowicz M, De Vera MA, et al. Immediate and past cumulative effects of oral glucocorticoids on the risk of acute myocardial infarction in rheumatoid arthritis: a population-based study. Rheumatology 2013; 52(1): 68-7.

35. Nurmohamed M, Choy E, Lula S, et al. The impact of biologics and tofacitinib on cardiovascular risk factors and outcomes in patients with rheumatic disease. Drug Saf 2018; 41(5): 473-88.

36. Puig L, Strohal R, Husni ME, et al. Cardiometabolic profile, clinical features, quality of life and treatment outcomes in patients with moderate-to-severe psoriasis and psoriatic arthritis. J Dermatolog Treat 2015; 26(1): 7-15.

37. Costa L, Caso F, Atteno M, et al. Impact of 24-month treatment with etanercept, adalimumab, or methotrexate on metabolic syndrome components in CV risk in RA patients treated with biologics or tofacitinib a cohort of 210 psoriatic arthritis patients. Clin Rheumatol 2014; 33(6): 833-9.

38. Van Dongen C, Agca R, Trivino L, Vogelzang E, Nurmohamed MT. Effect of etanercept therapy on lipid profile in patients with psoriatic arthritis. Ann Rheum Dis 2014; 73: 734-5.

39. De Sanctis S, Marcovecchio ML, Gaspari S, et al. Etanercept improves lipid profile and oxidative stress measures in patients with juvenile idiopathic arthritis. J Rheumatol 2013; 40(6): 943-8.

40. Gladman DD, Farewell VT, Wong K, et al. Mortality studies in psoriatic arthritis: results from a single outpatient center. II. Prognostic indicators for death. Arthritis Rheum 1998; 41(6): 1103-10.

41. Fenyo IM, Gafencu AV. The involvement of the monocytes/macrophages in chronic anflammation associated with atherosclerosis. Immunobiology 2013; 218(11): 1376-84.

42. Mestas J, Ley K. Monocyte-endothelial cell interaction in the development of atherosclerosis. Trends Cardiovasc Med 2008; 18(6): 228-32.

43. Fon Tacer K, Kuzman D, Seliskar M, et al. TNF - alpha interferes with lipid homeostasis and activates acute and proatherogenic processes. Physiol Genomics 2007; 31(2): 216-27

44. Zhang $\mathrm{H}$, Park $\mathrm{Y}$, Chen $\mathrm{X}$, et al. Role of anti TNF - alpha in vascular dysfunction. Clin Sci (Lond) 2009; 116: 219-30.

45. Sattar N, McCarey DW, Capell H, McInnes IB. Explaining how "highgrade" systemic inflammation accelerates vascular risk in rheumatoid arthritis. Circulation 2003; 108(24): 2957-63.

46. Hinks A, Martin P, Flynn E, et al. Investigation of type 1 diabetes and coeliac disease susceptibility loci for association with juvenile idiopathic arthritis. Ann Rheum Dis 2010; 69(12): 2169-72.

47. Vojtková J, Ciljaková M, Michnová Z, Turčan T. Chronic complications of diabetes mellitus related to the respiratory system. Pediatr Endocrinol Diabetes Metab 2012; 18(3): 112-5.

48. Edwards NM, Daniels SR, Claytor RP, et al. Physical activity is independently associated with multiple measures of arterial stiffness in adolescents and young adults. Metabolism 2012; 61(6): 869-72.

49. De Sanctis S, Marcovecchio ML, Gaspari S, et al. Etanercept improves lipid profile and oxidative stress measures in patients with juvenile idiopathic arthritis. J Rheumatol 2013; 40(6): 943-8.

50. Prati C, Demougeot C, Guillot X, Godfrin-Valnet M, Wendling D. Endothelial dysfunction in joint disease. Joint Bone Spine 2014; 81(5): 386-91.

51. Hjeltnes G, Hollan I, Forre O, et al. Endothelial function improves within 6 weeks of treatment with methotrexate or methotrexate in combinationwith a TNF-alpha inhibitor in rheumatoid arthritis patients. Scand J Rheumatol 2012; 41(3): 240-42.

52. Van Eijk IC, Peters MJ, Serne EH, et al. Microvascular function is impaired in ankylosing spondylitis and improves after tumour necrosis factor-alpha blockade. Ann Rheum Dis 2009; 68(3): 362-66.

53. Syngle A, Vohra K, Sharma A, Kaur L. Endothelial dysfunction in ankylosing spondylitis improves after tumor necrosis factor-alpha blockade. Clin Rheumatol 2010; 29(7): 763-70. 